\title{
Predicting the Determinants of Dynamic Geometry Software Acceptance: A Two-Staged Structural Equation Modeling - Neural Network Approach
}

\author{
Chiu-Liang Chen
}

\begin{abstract}
This research examined the predictors of dynamic geometry software adoption by using GeoGebra as a case study. The proposed model incorporated basic predictors of the technology acceptance model such as perceived usefulness (PU), perceived ease of use (PEOU), and attitude toward usage (ATU), as well as predictors relating to students' mathematics attitudes, namely self-confidence in mathematics, perceived value of mathematics (VAL), and enjoyment of mathematics. Data were collected from 175 students who had applied GeoGebra for their mathematics learning, and a two-stage hybrid structural equation modeling (SEM)-neural network approach was employed to test the proposed research model. First, the variables significantly influencing GeoGebra usage intention were identified through SEM. Subsequently, the identified predictors were ranked in terms of their relative influence by using a neural network model. The results showed that PU, PEOU, ATU, and VAL had significant effects on students' behavioral intentions to use GeoGebra, and PU was the most significant predictor of students' intentions to use GeoGebra in mathematics learning, followed by PEOU, ATU, and VAL. The results of this study could be useful for teachers to formulate effective strategies of integrating dynamic geometry software into their mathematics teaching.
\end{abstract}

Index Terms-Dynamic geometry software, GeoGebra, structural equation modeling, technology acceptance model.

\section{INTRODUCTION}

Information and communications technology (ICT) has been comprehensively applied in mathematics education. Numerous studies have investigated the application of various types of ICT for various learning topics. For example the open-source language $\mathrm{R}$ was applied to implement an inquiry-based course in introductory statistics [1]. Open-source software wxMaxima was used to teach calculus [2]. Simulation has been adopted to enhance students' knowledge of relevant abstract concepts involved in correlation [3] and probability [4], and computer games have been applied to support algebra learning [5], [6].

The National Council of Teachers of Mathematics (NCTM) uses five process standards - problem solving, reasoning and proof, communication, connections, and representation-to highlight ways of acquiring and using mathematical knowledge, and uses five content standards-number and operations, algebra, geometry, measurement, and data analysis and probability - to explicitly describe content that students should learn from prekindergarten to grade 12 [7].

Manuscript received October 12, 2019; revised March 31, 2020.

The author is with National Taipei University of Business, Taiwan (e-mail: ccliang@ntub.edu.tw).
The NCTM proposed that the importance of using multiple representations should be emphasized throughout students' mathematical education. Graphing calculators and dynamic geometry software (DGS) are types of ICT that exhibit the advantage of supporting visual reasoning and multiple representations; thus, they have been widely applied to teach algebra and geometry.

Graphing calculators and their built-in mathematics analysis software enable learners to simultaneously manipulate and observe the characteristics of functions from graphical, numerical, and algebraic representations. Numerous studies have indicated that such learning processes enhance students' conceptual understanding [8]-[10]. Applying DGS to algebra teaching has the same advantage as that of using graphing calculators. Moreover, DGS generates various geometric figures by constructing instead of drawing, thereby enabling learners to understand the characteristics of such figures through visual reasoning during construction. A few studies have proposed that application of DGS in teaching exhibits favorable learning effects compared with conventional classroom teaching Related research is comprehensively introduced in Section 2.A.

Based on the usefulness of DGS in mathematic learning, its successful integration into mathematics teaching is a topic worthy of exploration, and learners' intention to use such software is a vital element. Therefore, factors that affect learners' intention to use DGS should be identified first. Thus, this study used GeoGebra as a case study to propose a new research model to predict the most significant factors influencing the intention to use DGS. The proposed model includes common predictors of new technology adoption, including perceived usefulness (PU), perceived ease of use (PEOU), and attitude toward usage (ATU). Moreover, the model contains variables associated with students' mathematics attitudes, including perceived value of mathematics (VAL), enjoyment of mathematics (ENJ), and self-confidence in mathematics (SC). The influences of variables related to attitudes toward mathematics on use of GeoGebra are seldom discussed.

The research objective was to identify the key factors affecting GeoGebra usage intention and their relative influences. Conventional statistical analysis examines only linear relationships among variables in terms of predicting users' behaviors. Neural networks can model complex nonlinear relationships, and thus can transcend this limitation. This study first used structural equation modeling (SEM) to identify variables that substantially affect software use 
intention and then adopted a neural network to determine the relative influences of these variables.

\section{LITERATURE REVIEW}

\section{A. DGS}

Commonly used DGS includes The Geometer's Sketchpad (GSP) [11], JavaSketchpad (JSP), Cabri Geometry [12], and GeoGebra [13]. JSP is designed to enable users to interact or publish sketches from GSP online. Extensive research has been conducted to explore application of the aforementioned software programs in mathematics teaching. This section reviews relevant studies on these programs.

Applications of GSP for teaching geometry include helping secondary school students achieve a favorable level of geometric thinking [14], assisting high school students in enhancing their inductive reasoning and conceptual knowledge in geometry learning [15], and substantially improving sixth grade students' performance in congruency and similarity of polygons [16]. Moreover, [17] investigated the effectiveness of using GSP to teach trigonometric functions and discovered that the learning performance of their experimental group (using GSP) was substantially higher than that of their control group.

Previous studies have shown that applying Cabri Geometry for teaching can enhance students' abilities for problem solving, reasoning, and proofs. Reference [18] analyzed high school teachers' processes of solving optimization problems; the researchers proposed that Cabri Geometry could enhance learners' abilities to think mathematically and implement heuristic strategies in problem-solving processes. Regarding reasoning and proof, [19] examined high school students' plausible methods for dividing a square into two equal areas; the research findings indicated that the use of Cabri Geometry provided students with methods of initially formulating a conjecture and subsequently developing an argument to support it. Reference [20] analyzed methods adopted by students to prove trigonometry theorems. Based on students' proofs, the researchers found that Cabri Geometry helped the students to discover and verify conjectures. This advantage improved the students' ability to prove theorems from naïve empiricism to deduction.

GeoGebra is a freely available open-source mathematics program developed by Markus Hohenwarter [13]. GeoGebra has been applied to mathematics education in the following two manners. (i) First, it has been applied to assess the effect of introducing software in teaching concepts including statistics [21], calculus [22], [23], functions, equations, inequalities [24]-[26], and analytic geometry [27]. The studies above noted that GeoGebra can improve students' learning outcomes compared with conventional classroom-based teaching. (ii) GeoGebra has also been applied for the professional development of mathematics teachers on teaching concepts such as calculus [28], [29], and mathematics visualization skills [30].

The aforementioned studies have focused on analyzing the effects of GeoGebra application; by contrast, little attention has been paid to the intention to use DGS. The present study sought related studies in the Scopus database but found only four studies that have investigated attitudes toward intentions to use DGS based on the TAM or other theories. Table I lists the DGS and models adopted by these four studies. Section III refers to the factors identified by these four studies to propose the research model and hypotheses of the present study.

TABLE I: RELATED STUDIES ON INTENTIONS TO USE DGS

\begin{tabular}{lll}
\hline \hline DGS & Model Applied & References \\
\hline GeoGebra & TAM & {$[31]$} \\
GeoGebra & TAM & {$[32]$} \\
Geometer's & TAM & {$[33]$} \\
Sketchpad & Technological pedagogical content & \\
Fathom & knowledge (TPACK) & \\
GeoGebra, & Combination of TAM, Theory of planned & {$[34]$} \\
Cabri, & behavior (TPB), and Theory of innovation & \\
Geometer's & diffusion (IDT) & \\
Sketchpad & & \\
\hline \hline
\end{tabular}

\section{B. TAM}

The TAM was introduced as an adaptation of the theory of reasoned action (TRA) [35], [36]. The TAM was specifically developed to predict and explain computer usage, and uses the TRA as a theoretical basis for establishing causal linkages between the constructs of PU, PEOU, ATU, behavioral intention to use, and actual use of technology. Many studies have integrated the TAM into their research models to analyze factors that influence the behavioral intention to adopt various ICTs in education, including mobile learning [37], [38], cloud computing at universities [39], [40], social media in higher education [41]-[43], electronic portfolios [44], the Line mobile app for English oral training [45], and massive open online courses [46].

\section{ATMI}

Reference [47] developed the ATMI for high school students; the ATMI comprises four factors, namely ENJ, motivation to do mathematics (MOT), SC, and VAL, and 40 items under these four factors. To examine whether ATMI is valid for other student groups, it was tested on 134 American college students through the execution of confirmatory factor analysis (CFA); the executed CFA revealed high reliability as well as internal consistency, indicating that this four-factor model is valid for college students [48].

Reference [49] claimed that extant measures of mathematics attitudes have several drawbacks, such as being very lengthy, dated, and tested solely on Western participants. Therefore, they developed a shortened adaptation of the ATMI (hereafter referred to as "short ATMI") that operationalizes the same factors as the ATMI and further tested this version on a sample of mathematics students from six of the twenty-one pretertiary institutions in Singapore (i.e., Asian participants). The CFA results supported the original four-factor model, from which five ENJ, one MOT, ten SC, and five VAL items were effectively redundant and thus removed. This resulted in only 19 remaining items (five ENJ, four MOT, five SC, and five VAL items) in the short ATMI. Reference [49] reported that the ENJ-MOT correlation was notably high, at $r=.96$, confirming that using both subscales is essentially redundant. Based on two more rounds of CFA, 
they suggested that the MOT subscale be excluded from future applications of this model.

In view of a lack of up-to-date Chinese language instruments that measure Taiwanese students' attitudes toward mathematics, [50] developed a Chinese version of the short ATMI and explored its validity for assessing Taiwanese undergraduates based on the studies of [47]-[49]. After statistical examination through exploratory factor analysis and CFA, five of the short ATMI's 19 items were removed, leaving only $4 \mathrm{VAL}, 4 \mathrm{SC}, 3 \mathrm{ENJ}$, and 3 MOT items in the Chinese version of the short ATMI. All results suggested that the Chinese version of the short ATMI had high internal consistency, convergent validity, discriminant validity, and factorial validity.

\section{SEM-Neural Network Modeling}

Traditional linear statistical techniques-for example, multiple regression analysis and SEM-entail the examination of only linear models; thus, complex decisions related to the adoption of technologies obtained using these methods may be oversimplified. To overcome this limitation, the neural network approach is incorporated to identify nonlinear relationships in the research model. In this two-stage method, first, SEM is employed to test the overall research model and hypothesized relationships. Second, the relative influence of SEM-derived significant predictors is ranked using a neural network model. This addresses a weakness of the neural network, namely the tendency to overfit a model, while improving the accuracy of predictions compared with traditional regression techniques.

Previous studies have applied the SEM-neural network approach to predict determinants of Facebook usage in higher education [43], mobile payment [51], mobile banking [52], and e-learning management systems [53]. However, no research has applied the aforementioned two-stage SEM-neural network approach to predict determinants of DGS acceptance.

\section{RESEARCH MODEL AND HYPOTHESES}

Table I lists the aforementioned four studies that have applied the TAM and other theories to explore attitudes toward intentions to adopt and use DGS. Three of the studies primarily adopted GeoGebra as the DGS, and their proposed research models all contain three variables: PU, PEOU, and behavioral intention. Except for [33], the other three studies also mentioned ATU as a variable. Based on the literature review, the research model in the present study adopted PU, PEOU, and ATU as independent variables and behavioral intention as the dependent variable.

Because DGS was developed specifically for mathematics learning, students' mathematics attitudes affect their willingness to use such software. However, constructs considered in previous studies have been limited to TAM-related variables such as PU, PEOU, and ATU; constructs related to mathematics attitudes were not considered. Therefore, in addition to the TAM constructs, this study added three mathematics attitude-related factors to the research model.

This study used the Chinese version of the short ATMI developed by [50] for Taiwanese undergraduates. Similar to the ATMI developed by [47], [48] and the short ATMI developed by [49], the Chinese version of the short ATMI contains four subscales: ENJ, MOT, SC, and VAL. Because the correlation between the ENJ and MOT subscales was nearly 1, the MOT subscale was excluded based on the recommendation of [49]; therefore, the research model of the present study contained the three subscales of ENJ, SC, and VAL from the Chinese version of the short ATMI.

Following the literature review, the research model in this study contained six independent variables: PU, PEOU, ATU, ENJ, SC, and VAL. Behavioral intention was the dependent variable. The following subsections discuss the meaning and associated research hypothesis of each variable.

\section{A. $P U$}

PU, defined as "the degree to which a person believes that using a particular system would enhance his or her job performance" [54] (p. 320), is hypothesized to be a fundamental determinant of technology adoption. The results of [31] and [32] revealed that PU exerted a considerable influence on students' attitudes toward usage of GeoGebra. This study analyzed the effect of PU on behavioral intention and proposed the following hypothesis.

$\mathrm{H} 1$ : PU has a significant influence on behavioral intention to use DGS.

\section{B. $P E O U$}

Like PU, PEOU is one of the original TAM variables and is hypothesized to be a fundamental determinant of technology acceptance [54]. PEOU refers to "the degree to which a person believes that using a particular system would be free of effort" [54] (p. 320).

The four studies listed in Table I reached different conclusions regarding how PEOU affects PU and ATU. Reference [31] and [32] have proposed that PEOU has a significant relationship with PU and a significant effect on students' ATU of GeoGebra. Reference [55] indicated that PEOU of DGS had a negative but nonsignificant influence on ATU. According to [33], PEOU did not unilaterally predict PU; rather, these two factors mutually affected each other.

This study tested the effect of PEOU on behavioral intention and proposed the following hypothesis.

$\mathrm{H} 2$ : PEOU has a significant influence on behavioral intention to use DGS.

\section{C. $A T U$}

According to the TRA, attitude is defined as an individual's positive or negative feelings (evaluative affect) about performing a target behavior [36]. Moreover, the TRA and TAM indicate that ATU is a determinant of behavioral intention. Among the four studies in Table I, only the research model developed by [33] did not consider ATU; the other three studies found positive and statistically significant correlations between ATU and behavioral intention toward DGS.

Thus, this study proposed the following hypothesis.

H3: ATU has a significant influence on behavioral intention to use DGS.

\section{Factors of Mathematical Attitudes}


The three subscales of ENJ, SC, and VAL in the Chinese version of the short ATMI developed by [50] were included in the present research model. According to [47], [48], the ENJ subscale measures the degree to which students enjoy working on mathematics, the SC subscale measures students' confidence and self-concept of their performance in mathematics, and the VAL subscale measures students' beliefs on the usefulness, relevance, and worth of mathematics to their lives.

Therefore, the following hypotheses were formulated.

H4: ENJ has a significant influence on students' behavioral intention to use DGS.

H5: SC has a significant influence on students' behavioral intention to use DGS.

H6: VAL has a significant influence on students' behavioral intention to use DGS.

\section{E. Behavioral Intention}

Behavioral intention (BI) is a measure of the strength of one's intention to perform a specified behavior [36]. Reference [56] empirically examined the ability of the TRA and TAM to predict and explain user acceptance and rejection of computer-based technology and concluded that people's levels of computer use can be predicted reasonably accurately based on their intentions. Therefore, this study adopted behavioral intention as the dependent variable. The research model, which consisted of six predictors of intention to use DGS, is illustrated in Fig. 1.

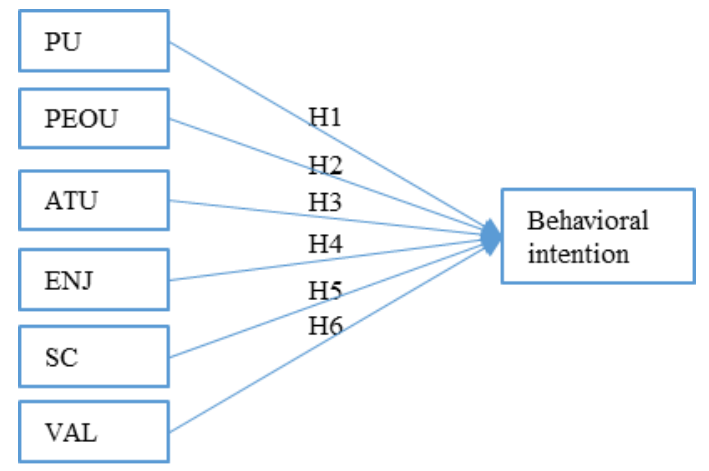

Fig. 1. Research model.

\section{Methods}

\section{A. Survey Instrument}

A survey questionnaire was developed to test the research model in this study. To measure the six independent variables and the dependent variable, 22 and 3 items were used, respectively. The items included in the questionnaire were based on a review of relevant studies. All items were measured on a 5-point Likert scale ranging from 1 (strongly disagree) to 5 (strongly agree). Table II shows the constructs, measurement items under each construct, and supporting studies for each construct.

TABLE II: MEASUREMENT ITEMS

\begin{tabular}{lll}
\hline \hline Construct & Items & References \\
\hline \multirow{2}{*}{ PU } & Applying GeoGebra to mathematical learning & {$[41],[42]$,} \\
& improves my conceptual understanding. & {$[54]$}
\end{tabular}

Applying GeoGebra to mathematical learning improves my problem-solving efficiency.

Applying GeoGebra to mathematical learning makes studying easier.

I think GeoGebra is effective for

mathematical learning.

PEOU I find GeoGebra easy to use.

[41], [42],

Learning to operate GeoGebra would be easy for me.

It would be easy for me to become skillful at using GeoGebra.

I always face problems when using GeoGebra.

ATU I have a positive attitude toward using GeoGebra for learning mathematics.

GeoGebra is a convenient tool for learning mathematics.

GeoGebra is a beneficial tool for learning mathematics.

I usually enjoy studying mathematics in school.

[47]-[50]

Mathematics is a very interesting subject.

I really like mathematics.

SC Studying mathematics makes me feel

nervous.

I am always under terrible strain in a mathematics class.

I am always confused in my mathematics class.

I feel a sense of insecurity when studying mathematics.

VAL Mathematics is a very worthwhile and necessary subject.

Mathematics is one of the most important subjects for people to study.

College mathematics lessons would be very helpful, no matter what I decide to study in the future.

Mathematics is important in everyday life.

I hope to continue using GeoGebra in other mathematics courses in the future.

I intend to continue exploring other applications of GeoGebra.

GeoGebra is a learning tool worth promoting.

\section{B. Research Participants and Data Collection}

The research participants were students from five classes at a public university in Northern Taiwan. Two of these classes studied trigonometric functions with GeoGebra. Two others were calculus classes, where the students learned to find open intervals in which a function increases or decreases, as well as the relative extrema and concavity with GeoGebra. The final class used GeoGebra to study data analysis and probability distribution. After completion of all classes, the survey instrument for this study was distributed among the students in their classrooms. The total number of questionnaires distributed was 199, and 175 (54 from males, 121 from females) completed questionnaires were obtained.

\section{DATA ANALYSIS AND FINDINGS}

Data analysis was conducted in two stages, with the first stage involving the use of the statistical software packages SPSS 20 and AMOS 18. In the first stage, SEM was applied to test the research hypotheses and reliability and validity of 
the measures. In the second stage, significant independent variables identified based on the SEM results were used as input variables in the neural network model to predict GeoGebra usage in mathematics learning.

\section{A. Reliability and Validity Analysis}

This study investigated the reliability, convergent validity, and discriminant validity of the constructs; the results are summarized in Table III. Composite reliability (CR) was greater than 0.70 for all constructs; therefore, construct reliability was confirmed [57]. Convergent validity was confirmed because all $\mathrm{CR}$ values were greater than the corresponding average variance extracted (AVE) values and all AVE values were greater than 0.50 [57]. Finally, for all variables, AVE > maximum shared squared variance $(\mathrm{MSV})$ and AVE > average shared squared variance (ASV), which confirmed discriminant validity. The goodness of fit of the overall CFA model was also tested. The values of fit indices in the proposed model were chi-square test statistic/degrees of freedom $=1.49$, normed fit index $=0.897$, goodness of fit index $=0.855$, adjusted goodness of fit index $=0.815$, comparative fit index $=0.963$, and root-mean-square error of approximation $=0.053$, indicating adequate model fit.

\begin{tabular}{lllll}
\multicolumn{4}{c}{ TABLE III: RELIABILITY AND VALIDITY OF CONSTRUCTS } \\
\hline \hline & CR & AVE & MSV & ASV \\
\hline VAL & 0.893 & 0.677 & 0.211 & 0.078 \\
SC & 0.930 & 0.769 & 0.378 & 0.119 \\
ENJ & 0.948 & 0.858 & 0.378 & 0.128 \\
ATU & 0.943 & 0.848 & 0.575 & 0.239 \\
PEOU & 0.909 & 0.720 & 0.575 & 0.201 \\
PU & 0.925 & 0.757 & 0.575 & 0.205 \\
\hline \hline
\end{tabular}

\section{B. Testing of Hypotheses}

Table IV presents the results of hypothesis testing; four of the six proposed hypotheses, namely $\mathrm{H} 1, \mathrm{H} 2, \mathrm{H} 3$, and H6, were accepted at the $5 \%$ level of significance. No confirmed significant effect of ENJ or SC on students' behavioral intention to use GeoGebra was observed; therefore, $\mathrm{H} 4$ and H5 were rejected, possibly because mathematics is a subject that is prone to learning difficulties, and thus some students have difficulty being interested in learning it. This phenomenon was verified by the questionnaire results of this study and other studies. (i) Of the six independent variables, only the scores of ENJ and SC were lower than "neutral", at 2.67 and 2.96, respectively; the remaining four were higher than "neutral" (PU, 3.57; PEOU, 3.46; ATU, 3.77; VAL, 3.42). (ii) Mathematics is a subject that often requires remedial teaching [58], [59]. Reference [58] quoted information published by American College Testing in 2012 and highlighted that $45 \%$ of all high school students in the United States met the mathematics benchmark, yet $80 \%$ of universities and $98 \%$ of community colleges place $20 \%-50 \%$ of first-year students in remedial courses. To render remedial teaching truly rewarding, [59] explored how an arithmetic immersion workshop prior to remedial teaching can help students benefit from such teaching.

\begin{tabular}{llllll}
\multicolumn{5}{c}{ TABLE IV: RESUlTS OF HYPOTHESIS TESTING } \\
\hline \multirow{2}{*}{ Variables } & $\begin{array}{l}\text { Path } \\
\text { Coefficients }\end{array}$ & $t$ values & $p$ values & Results \\
\hline H1 & PU & 0.423 & 5.761 & 0.000 & Supported \\
H2 & PEOU & 0.187 & 2.613 & 0.010 & Supported
\end{tabular}

\begin{tabular}{llllll} 
H3 & ATU & 0.258 & 3.037 & 0.003 & Supported \\
H4 & ENJ & -0.066 & -1.044 & 0.298 & Not supported \\
H5 & SC & -0.015 & -0.248 & 0.805 & Not supported \\
H6 & VAL & 0.107 & 2.007 & 0.046 & Supported \\
\hline
\end{tabular}

\section{Neural Network Results}

The neural network model developed using MATLAB 2017 was trained by the multilayer perceptron alongside a backpropagation training algorithm. The input layer consisted of the four significant independent variables from the SEM analysis (i.e., PU, PEOU, ATU, and VAL), whereas the dependent variable-behavioral intention-was included in the output layer of the network model. To avoid overfitting of the model, tenfold cross validation was performed as follows: of the datasets, $68.6 \%(120 / 175)$ and $31.4 \%$ were utilized to train and test the network, respectively. This model's prediction accuracy was determined by calculating the root-mean-square errors (RMSEs) of the training and testing datasets for all ten neural networks and the average for both datasets (Table V). The average RMSEs were determined to be 0.558 and 0.567 for the training and testing data, respectively (Table V). The sensitivity analysis results for input variables in the neural network model are presented in Table VI. PU was the most significant predictor of students' GeoGebra adoption in mathematics learning, followed by PEOU, ATU, and VAL.

TABLE V: RMSE VALUES FOR NEURAL NETWORKS

\begin{tabular}{lll}
\hline \hline Artificial Neural Networks & Training & Testing \\
\hline 1 & 0.432 & 0.525 \\
2 & 0.567 & 0.654 \\
3 & 0.531 & 0.679 \\
4 & 0.544 & 0.547 \\
5 & 0.664 & 0.742 \\
6 & 0.677 & 0.531 \\
7 & 0.579 & 0.672 \\
8 & 0.564 & 0.591 \\
9 & 0.563 & 0.412 \\
10 & 0.456 & 0.321 \\
Average & 0.558 & 0.567 \\
\hline \hline
\end{tabular}

TABLE VI: WEIGHT OF NORMALIZED VARIABLES

\begin{tabular}{ll}
\hline \hline Predictors & Normalized importance \\
\hline PU & 1 \\
PEOU & 0.93 \\
ATU & 0.89 \\
VAL & 0.82 \\
\hline \hline
\end{tabular}

Reference [56] empirically examined the ability of the TRA and TAM to predict and explain user acceptance and rejection of computer-based technology; their results indicated that PU was a major determinant and PEOU was a significant secondary determinant of people's intentions to use computers. Therefore, regarding the importance of PU and PEOU, the neural network results of this study yielded a similar conclusion to that of [56].

\section{CONCLUSION}

This study proposed and tested a new research model comprising six potential predictors of students' behavioral intention to use GeoGebra for mathematics learning by employing an SEM-neural network approach. All three TAM predictors, namely PU, PEOU, and ATU, and one 
mathematics attitude predictor, namely VAL, significantly influenced students' behavioral intentions to use GeoGebra. The neural network results indicated that the order of importance of the four factors that significantly affected students' behavioral intentions to use GeoGebra was PU, PEOU, ATU, and VAL.

\section{DISCUSSION}

This section discusses strategies for improving students' behavioral intentions to use DGS based on these four variables. PU was the most influential factor. Therefore, enhancing students' perceptions of usefulness of DGS could effectively improve their willingness to use such software. According to the NCTM principles and standards for school mathematics, five learning processes-problem solving, reasoning and proof, communication, connections, and representation —-were major methods for acquiring and using mathematical knowledge. Therefore, introducing DGS into mathematics teaching to enhance students' abilities to adopt these five learning processes in order to improve their perception of usefulness is an essential integration strategy. Numerous studies have explored how to integrate DGS (particularly GeoGebra) into teaching to enhance students' learning processes of problem solving [60], [61], reasoning and proof [60], [62], and representation [63], [64]. These studies could help to formulate teachers' strategies for enhancing students' mathematics learning processes, improving their perception of software usefulness, and consequently increasing their willingness to use software.

PEOU was the second most essential factor. When students first use DGS, preconstructed dynamic geometry materials enable them to focus on acquiring knowledge rather than on complicated operating steps; this is effective in improving PEOU. Reference [65] explored how a set of preconstructed dynamic geometry materials was designed to teach similar triangles; preconstructed DGS materials improved students' learning motivation and stimulated them to change their manners of thinking.

ATU was the third most essential factor. Reference [31] and [32] have indicated that PU and PEOU significantly influence students' ATU of GeoGebra. Therefore, improving PU and PEOU can enhance ATU and usage intention.

VAL was the least essential of the four factors. Reference [66] suggested that to promote VAL among adolescents, teachers must further understand how to employ real-world applications that are sensitive to race, context, and adolescent cognition in the classroom.

\section{LIMITATIONS AND FUTURE RESEARCH}

GeoGebra has a wide range of applications in mathematics learning. However, limited to learning topics taught in the classroom, this research could allow research participants to use GeoGebra to study only trigonometric functions, calculus, or statistics before the questionnaire was conducted. Directions for future research include how to enable research participants to acquire GeoGebra application experience for a wider range of learning topics before completing questionnaires, and research models based on theories other than the TAM and TRA.

\section{CONFLICT OF INTEREST}

The author declares no conflict of interest.

\section{AUTHOR CONTRIBUTIONS}

Ms. Chen conducted the research; analyzed the data; wrote the paper by herself.

\section{REFERENCES}

[1] C. Toews, "Computational inquiry in introductory statistics," PRIMUS, vol. 27, no. 7, pp. 707-724, 2017.

[2] A. F. M. Ayub, R. A. Tarmizi, K. A. Bakar, and W. S. Luan, "Adoption of WxMaxima software in the classroom: Effect on students' motivation and learning of mathematics," Malaysian Journal of Mathematical Sciences, vol. 8, no. 2, pp. 311-323, 2014.

[3] T. C. Liu, Y. C. Lin, and Kinshuk, "The application of simulation-assisted learning statistics (SALS) for correcting misconceptions and improving understanding of correlation," Journal of Computer Assisted Learning, vol. 26, no. 2, pp. 143-158, 2010.

[4] M. Trigueros, M. D. Lozano, and A. E. Lage, "Development and use of a computer-based interactive resource for teaching and learning probability in primary classrooms," International Journal for Technology in Mathematics Education, vol. 13, no. 4, pp. 205-211, 2006.

[5] M. V. D. Heuvel-Panhuizen, A. Kolovou, and A. Robitzsch, "Primary school students' strategies in early algebra problem solving supported by an online game," Educational Studies in Mathematics, vol. 84, no. 3, pp. 281-307, 2013.

[6] H. Panoutsopoulos and D. G. Sampson, "A study on exploiting commercial digital games into school context," Educational Technology \& Society, vol. 15, no. 1, pp. 15-27, 2012.

[7] National Council of Teachers of Mathematics, Principles and Standards for School Mathematics, Reston, VA: NCTM, 2000, ch. 3, pp. 29-71.

[8] N. W. Leng, "Using an advanced graphing calculator in the teaching and learning of calculus," International Journal of Mathematical Education in Science and Technology, vol. 42, no. 7, pp. 925-938, 2011.

[9] I. Lyublinskaya and N. Tournaki, "The effect of teaching and learning with Texas instruments handheld devices on student achievement in Algebra," Journal of Computers in Mathematics and Science Teaching, vol. 30, no. 1, pp. 5-35, 2011.

[10] C.-K. Tan and C.-P. Tan, "Effects of the handheld technology instructional approach on performances of students of different achievement levels," Computers \& Education, vol. 82, pp. 306-314, 2015.

[11] N. Jackiw, The Geometer's Sketchpad III, Berkeley, CA: Key Curriculum Press, 1995.

[12] Y. Baulac, F. Bellemain, and J. M., Laborde, Cabri II, Dallas, TX: Texas Instruments, 1994.

[13] M. Hohenwarter, "GeoGebra - A software system for dynamic geometry and algebra in the plane," M.S. thesis, Universit"at Salzburg, Salzburg, Austria, 2002.

[14] A. H. Abdullah and E. Zakaria, "Enhancing students' level of geometric thinking through van hiele's phase-based learning," Indian Journal of Science and Technology, vol. 6, no. 5, pp. 4432-4446, 2013.

[15] L. Ames, H. An, and S. Alon, The incorporation of geometer's sketchpad in a high school geometry curriculum," K-12 Education: Concepts, Methodologies, Tools, and Applications, IGI Global, 2013, pp. 639-646.

[16] A. K. Erbas and A. A. Yenmez, "The effect of inquiry-based explorations in a dynamic geometry environment on sixth grade students' achievements in polygons," Computers \& Education, vol. 57, no. 4, pp. 2462-2475, 2011.

[17] R. Ramli, R. Mustapha, and R. Ramli, "A study on the effectiveness of a technology supported approach in the teaching of mathematics Using Geometers' Sketchpad (GSP)," presented at the 2014 2nd International Conference on Technology, Informatics, Management, Engineering and Environment, TIME-E 2014, Indonesia.

[18] F. Barrera-Mora and A. Reyes-Rodríguez, "Cognitive processes developed by students when solving mathematical problems within 
technological environments," Mathematics Enthusiast, vol. 10, no. 1-2, pp. 109-136, 2013.

[19] M. Santos-Trigo and C. Cristobal-Escalante, "Emerging high school students' problem solving trajectories based on the use of dynamic software," Journal of Computers in Mathematics and Science Teaching, vol. 27, no. 3, pp. 325-340, 2008.

[20] J. Fiallo and A. Gutiérrez, "Analysis of the cognitive unity or rupture between conjecture and proof when learning to prove on a grade 10 trigonometry course," Educational Studies in Mathematics, vol. 96, no. 2, pp. 145-167, 2017.

[21] N. Arbain and N.A. Shukor, "The effects of GeoGebra on students achievement," Procedia - Social and Behavioral Sciences, vol. 172, pp. 208-214, 2015.

[22] D. Takaci, G. Stankov, and I. Milanovic, "Efficiency of learning environment using GeoGebra when calculus contents are learned in collaborative groups," Computers \& Education, vol. 82, pp. 421-431, 2015.

[23] E. Tatar and Y. Zengin, "Conceptual understanding of definite integral with GeoGebra," Computers in the Schools, vol. 33, no. 2, pp. 120-132, 2016.

[24] V. Akçakın, "Teaching mathematical functions using geometric functions approach and its effect on ninth grade students' motivation," International Journal of Instruction, vol. 11, no. 1, pp. 17-32, 2018.

[25] Hutkemri, S. N. A. S. Zamri, and E. Zakaria, "Conceptual and procedural knowledge: An effectiveness study on GeoGebra software," Advanced Science Letters, vol. 23, no. 3, pp. 2079-2082, 2017.

[26] J. N. A. Urgena and M. R. C. Lapinid, "The use of GeoGebra applets: Students' attitudes and achievement in learning quadratic functions, equations and inequalities," Advanced Science Letters, vol. 23, no. 2, pp. 1118-1121, 2017.

[27] M. Khalil, R. A. Farooq, E. Çakıroğlu, U. Khalil, and D. M. Khan, "The development of mathematical achievement in analytic geometry of grade-12 students through GeoGebra activities," EURASIA Journal of Mathematics, Science and Technology Education, vol. 14, no. 4, pp. 1453-1463, 2018.

[28] G. Caglayan, "Teaching ideas and activities for classroom: integrating technology into the pedagogy of integral calculus and the approximation of definite integrals," International Journal of Mathematical Education in Science and Technology, vol. 47, no. 8, pp. 1261-1279, 2016.

[29] N. C. Verhoef, F. Coenders, J. M. Pieters, D. Smaalen, and D. O. Tall, "Professional development through lesson study: Teaching the derivative using GeoGebra," Professional Development in Education, vol. 41, no. 1, pp. 109-126, 2015.

[30] M. Dockendorff and H. Solar, "ICT integration in mathematics initial teacher training and its impact on visualization: the case of GeoGebra," International Journal of Mathematical Education in Science and Technology, vol. 49, no. 1, pp. 66-84, 2018.

[31] S. A. P. Rajagopal, Z. Ismail, M. Ali, and N. Sulaiman, "Attitude of secondary students towards the use of GeoGebra in learning loci in two dimensions," International Education Studies, vol. 8, no. 13, pp. 27-32, 2015.

[32] J. N. A. Urgena and M. R. C. Lapinid, "The use of GeoGebra applets: Students' attitudes and achievement in learning quadratic functions, equations and inequalities," Advanced Science Letters, vol. 23, no. 2, pp. 1118-1121, 2017

[33] S. Okumus, L. Lewis, E. Wiebe, and K. Hollebrands, "Utility and usability as factors influencing teacher decisions about software integration," Educational Technology Research and Development, vol. 64, no. 6, pp. 1227-1249, 2016.

[34] G. Stols and J. Kriek, "Why don't all maths teachers use dynamic geometry software in their classrooms?" Australasian Journal of Educational Technology, vol. 27, no. 1, pp. 137-151, 2011.

[35] F. D. Davis, "A technology acceptance model for empirically testing new end-user information systems: theory and results," Doctoral dissertation, Sloan School of Management, Massachusetts Institute of Technology, 1986.

[36] M. Fishbein and I. Ajzen, Belief, Attitude, Intention and Behavior: An introduction to Theory and Research, Addison-Wesley, Reading, MA, 1975.

[37] L. Briz-Ponce, A. Pereira, L. Carvalho, J. A. Juanes- Mendez, and F. J. e. García-Penalvo, "Learning with mobile technologies - Students' behavior," Computers in Human Behavior, vol. 72, pp. 612-620, 2017.
[38] N. M. Sabah, "Exploring students' awareness and perceptions: Influencing factors and individual differences driving m-learning adoption," Computers in Human Behavior, vol. 65, pp. 522-533, 2016.

[39] I. Arpaci, "Antecedents and consequences of cloud computing adoption in education to achieve knowledge management," Computers in Human Behavior, vol. 70, pp. 382-390, 2017.

[40] H. M. Sabi, F.-M. E. Uzoka, K. Langmia, and F. N. Njeh, "Conceptualizing a model for adoption of cloud computing in education," International Journal of Information Management, vol. 36 , no. 2, pp. 183-191, 2016.

[41] I. Akman and C. Turhan, "User acceptance of social learning systems in higher education: An application of the extended technology acceptance model," Innovations in Education and Teaching International, vol. 54, no. 3, pp. 229-237, 2017.

[42] D. Z. Dumpit and C. J. Fernandez, "Analysis of the use of social media in higher education institutions (HEIs) using the technology acceptance model," International Journal of Educational Technology in Higher Education, vol. 14, no. 1, 2017

[43] S. K. Sharma, A. Joshi, and H. Sharma, "A multi-analytical approach to predict the Facebook usage in higher education," Computers in Human Behavior, vol. 55, no. 1, pp. 340-353, 2016.

[44] F. Abdullah, R. Ward, and E. Ahmed, "Investigating the influence of the most commonly used external variables of TAM on students' perceived ease of use (PEOU) and perceived usefulness (PU) of e-portfolios," Computers in Human Behavior, vol. 63, pp. 75-90, 2016

[45] J. S. C. Hsieh, Y.-M. Huang, and W.-C. V. Wu, "Technological acceptance of LINE in flipped EFL oral training," Computers in Human Behavior, vol. 70, pp. 178-190, 2017.

[46] $\mathrm{B}$. Wu and $\mathrm{X}$. Chen, "Continuance intention to use MOOCs: Integrating the technology acceptance model (TAM) and task technology fit (TTF) model," Computers in Human Behavior, vol. 67 , pp. 221-232, 2017.

[47] M. Tapia and G. E. II. Marsh, 'An instrument to measure mathematics attitudes,” Academic Exchange Quarterly, vol. 8, no. 2, pp. 16-21, 2004.

[48] M. Tapia and G. E. II. Marsh, "Attitudes toward mathematics inventory redux," Academic Exchange Quarterly, vol. 9, no. 3, pp. 272-275, 2005

[49] S. Y. Lim and E. Chapman, "Development of a short form of the attitudes toward mathematics inventory," Educational Studies in Mathematics, vol. 82, no. 1, pp. 145-164, 2013.

[50] S.-H. Lin and Y.-C. Huang, "Development and application of a Chinese version of the short attitudes toward mathematics inventory," International Journal of Science and Mathematics Education, vol. 14, no. 1, pp. 193-216, 2016

[51] F. Liébana-Cabanillas, V. Marinković, I. R. D. Luna, and Z. Kalinić, "Predicting the determinants of mobile payment acceptance: A hybrid SEM-neural network approach," Technological Forecasting \& Social Change, vol. 129, pp. 117-130, 2018.

[52] S. K. Sharma, "Integrating cognitive antecedents into TAM to explain mobile banking behavioral intention: A SEM-neural network modeling," Information Systems Frontiers, vol. 21, no. 4, pp. 815-827, 2019.

[53] S. K. Sharma, A. Gaur, V. Saddikuti, and A. Rastogi, "Structural equation model (SEM)-neural network (NN) model for predicting quality determinants of e-learning management systems," Behaviour \& Information Technology, vol. 36, no. 10, pp. 1053-1066, 2017.

[54] F. D. Davis, "Perceived usefulness, perceived ease of use, and user acceptance of information technology," MIS Quarterly, vol. 13, pp. 319-340, 1989.

[55] G. Stols, and J. Kriek, "Why don't all maths teachers use dynamic geometry software in their classrooms?" Australasian Journal of Educational Technology, vol. 27, no. 1, pp. 137-151, 2011.

[56] F. D. Davis, R. P. Bagozzi, and P. R. Warshaw, "User acceptance of computer technology: A comparison of two theoretical models," Management Science, vol. 35, no. 8, pp. 982-1003, 1989.

[57] F. J. Hair, W. Black, B. Babin, and R. Anderson, Multivariate Data Analysis: A Global Perspective, New Jersey: Pearson Education Inc, 2010. 
[58] C. M. Foshee, S. N. Elliott, and R. K. Atkinson, "Technology-enhanced learning in college mathematics remediation," British Journal of Educational Technology, vol. 47, no. 5, pp. 893-905, 2016.

[59] K. A. Parker, "A modularized tablet-based approach to preparation for remedial mathematics," International Journal of Mathematical Education in Science and Technology, vol. 47, no. 8, pp. 1244-1260, 2016.

[60] C. Granberg and J. Olsson, "ICT-supported problem solving and collaborative creative reasoning: Exploring linear functions using dynamic mathematics software," The Journal of Mathematical Behavior, vol. 37, pp. 48-62, 2015.

[61] K. M. Kim and R. Md-Ali, "GeoGebra: Towards realizing 21st century learning in mathematics education," Malaysian Journal of Learning and Instruction, pp. 93-115, 2017.

[62] M. Abánades, F. Botana, Z. Kovács, T. Recio, and C. Sólyom-Gecse, "Development of automatic reasoning tools in GeoGebra," ACM Communications in Computer Algebra, vol. 50, no. 3, pp. 85-88, 2016.

[63] A. Anabousy, W. Daher, N. Baya'a, and M. Abu-Naja, "Conceiving function transformations in different representations: Middle school students working with technology," Mathematics Education, vol. 9, no. 2, pp. 97-112, 2014.

[64] M. Stupel and D. Ben-Chaim, "Absolute value equations - What can we learn from their graphical representation?" International Journal of Mathematical Education in Science and Technology, vol. 45, no. 6, pp. 923-928, 2014.

[65] K. K. Poon and K. L. Wong, "Pre-constructed dynamic geometry materials in the classroom - how do they facilitate the learning of 'Similar Triangles'?" International Journal of Mathematical
Education in Science and Technology, vol. 48, no. 5, pp. pp. 735-755, 2017.

[66] J. S. Matthews, "When am I ever going to use this in the real world? Cognitive flexibility and urban adolescents' negotiation of the value of mathematics," Journal of Educational Psychology, vol. 110, no. 5, pp. 726-746, 2018.

Copyright $\odot 2020$ by the authors. This is an open access article distributed under the Creative Commons Attribution License which permits unrestricted use, distribution, and reproduction in any medium, provided the original work is properly cited (CC BY 4.0).

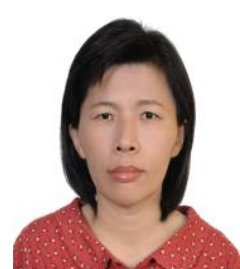

Chiu-Liang Chen was born in Taiwan in 1966. She received her bachelor's degree in computer science from Soochow University (Taipei City, Taiwan) in 1989 and her master's degree in electronic and computer engineering from National Taiwan University of Science and Technology in 1997. She is currently a full-time lecturer in the Department of Information Management, National Taipei University of Business. Her major field of study is ICT-integrated mathematics instruction.

Selected Publications: Chen, C.-L. \& Wu, C.-C. (2020). Students' behavioral intention to use and achievements in ICT-Integrated mathematics remedial instruction: Case study of a calculus course. Computers \& Education, 145. 